\title{
The nitric oxide donor LA 419 decreases ischemic brain damage
}

\author{
JULIA SERRANO $^{1 *}$, ANA PATRICIA FERNÁNDEZ ${ }^{1 *}$, RICARDO MARTÍNEZ-MURILLO $^{1}$, DAVID ALONSO $^{2}$, \\ JOSÉ RODRIGO ${ }^{1}$, EDUARDO SALAS ${ }^{3,4}$, MARISABEL MOURELLE $^{3}$ and ALFREDO MARTÍNEZ ${ }^{1}$ \\ ${ }^{1}$ Department of Neuroanatomy and Cell Biology, Instituto Cajal, CSIC; ${ }^{2}$ Pharmacology Department, \\ Medical School, Universidad Complutense, Madrid; ${ }^{3}$ Research and Development, Lácer, S.A., Barcelona, Spain
}

Received August 18, 2006; Accepted October 30, 2006

\begin{abstract}
Stroke represents a major clinical problem with limited available therapeutic treatments. Nitric oxide (NO) and the enzymes that produce it are involved in the pathogenesis of this disease. Here we investigated whether the novel NO donor LA 419 was able to ameliorate the consequences of stroke in an experimental model of global ischemia. We observed a sharp increase in the amounts of inducible NO synthase (iNOS) and nitrotyrosine in the cerebral cortex of experimental rats and a moderate increase of neuronal NO synthase (nNOS), as demonstrated by immunohistochemistry, Western blotting, and enzymatic activity assays. Treatment of these animals with LA 419 completely prevented ischemia-induced upregulation of nitrergic markers. Magnetic resonance imaging of the experimental brains showed a marked decrease in apparent diffusion coefficient (ADC) following ischemia-reperfusion, which was significantly corrected by pre-treatment with LA 419. These results clearly show that LA 419 is an efficient modulator of NO-related pathophysiological events and could eventually be used for the treatment of patients with cerebrovascular pathologies.
\end{abstract}

\section{Introduction}

Stroke is one of the main causes of death and a major cause of long-term disability in the western world. Indeed, stroke accounted for more than 1 in every 15 deaths in the United States in 2003 (http://www.americanheart.org). More than

Correspondence to: Dr Alfredo Martínez, Department of Neuroanatomy and Cell Biology, Instituto Cajal, CSIC, Avenida del Doctor Arce 37, 28002 Madrid, Spain

E-mail: amartinez@cajal.csic.es

Present address: ${ }^{4}$ Gendiag, S.L., Barcelona, Spain

${ }^{*}$ Contributed equally

Key words: nitric oxide donor, brain ischemia, neuronal nitric oxide synthase, inducible nitric oxide synthase, nitrotyrosine, magnetic resonance imaging
$80 \%$ of all strokes are caused by cerebral ischemia (1), resulting in devastating neurological sequelae accompanied by severe morphological and molecular alterations (2).

Since stroke is common and current drug therapies for the management of stroke patients are limited (3), there is a need for the identification of new targets and the development of new drugs (4). In the last decade several studies have examined the role of nitric oxide (NO) and nitric oxide synthase (NOS) in cardiac and cerebral ischemia (5-7). From these studies, it is becoming clear that both NO levels (4,8-10) and NOS activity (11) are increased in the heart and brain following ischemia, and that the nitrergic system is a good target for neuroprotection during stroke incidents (12).

The functional contributions of the different NOS isoforms to cerebral and cardiac stroke have been studied with genetically engineered mice where one of the isoforms had been knocked out, and using specific biochemical inhibitors. From these studies, we can conclude that inducible NOS (iNOS) expression contributes to ischemic damage, both in the brain (13) and in the heart (14). In contrast, endothelial NOS (eNOS) is always protective and eNOS-null mice suffered greater damage following brain (15) and heart (16) ischemia than their wild-type littermates. In addition, inhibitors of eNOS such as L-N-nitroarginine provoked stroke in stroke-prone spontaneously hypertensive rats, as well as in other rat strains (17). The impact of neuronal NOS (nNOS) in stroke is more complex and seems to be contextspecific. For instance, while nNOS-null mice developed a smaller infarct volume than control animals in models of cerebral ischemia (18), they showed higher mortality and heart remodeling following myocardial infarction (19). Whether nNOS is protective or deleterious is also sexdependent $(20,21)$.

LA 419 is a novel NO donor that has been designed to treat clinical conditions associated with a reduced bioavailability of NO (22). LA 419 has been shown to exert heart anti-ischemic, anti-thrombotic, as well as antiatherosclerotic actions (22-24), but so far no studies have been performed on the protective effects of this drug in cerebral ischemia.

The aim of the present study was to determine the effects of LA 419 treatment in a model of global brain ischemia by immunohistochemistry, Western blotting, enzyme activity assays, and magnetic resonance imaging (MRI) in the absence and presence of the NO donor. The cerebral cortex 
was studied, since our previous study focused on this same area (25). Very significant differences in the expression of nNOS, iNOS, and nitrotyrosine, as well as in brain imaging, after treatment with LA 419 of ischemic animals suggest that this chemical may be useful to prevent and/or treat ischemic damage.

\section{Materials and methods}

Animals. Male Wistar rats $(\mathrm{n}=56)$ provided by Harlan (Barcelona, Spain) weighing 250-350 g were housed in a conventional animal facility where the environmental temperature and relative humidity were monitored and controlled. The animals had free access to food and water except when otherwise specified. The lighting schedule in the animal facility was $12 \mathrm{~h}$ light/12 h dark. After a 1 -week quarantine period, animals included in the protocol were fasted overnight before the study. All procedures were carried out in accordance with the European Communities Council Directive (86/609/EEC) on animal experiments, under a protocol approved by the Animal Welfare Committee of the Cajal Institute.

Administration of LA 419. After a food fasting period of $8 \mathrm{~h}$, LA 419 was given by oral gavage in a vehicle consisting of $1 \%$ Cremophor EL 27963, 1\% Tween-80 and 0.5\% Methocel E-15 in distilled water at the indicated concentrations. The calculated ED50 for LA 419 in rats is $28 \mu \mathrm{mol} / \mathrm{kg}(=7 \mathrm{mg} /$ $\mathrm{kg}$ ) (Lácer, unpublished results). For our experiments we chose a dose slightly higher $(20 \mathrm{mg} / \mathrm{kg})$ to ascertain proper drug saturation.

Perfusion model of global cerebral ischemia. A perfusion model of global cerebral ischemia was used as described $(26,27)$. Control rats $(n=7)$, which were not subjected to ischemia-reperfusion, were anesthetized with equithesin (150 mg/kg chloral hydrate and $34 \mathrm{mg} / \mathrm{kg}$ pentobarbital) and perfused intracardialy with $100 \mathrm{ml}$ saline. The brains were collected for either Western blotting and enzyme activity assays $(n=4)$, or followed by perfusion with $350 \mathrm{ml}$ of fixative solution as described below for immunohistochemistry $(n=3)$.

The animals subjected to ischemia-reperfusion $(n=21)$ were perfused with the help of a peristaltic pump at $5 \mathrm{ml} /$ min via the left ventricle with an oxygenated buffered plasma substitute (Hemoce, Hoechst Farma, Barcelona, Spain) enriched with $11 \mathrm{mM}$ glucose as described $(26,27)$. The perfusion protocol began with a 15-min 'protection' period in which the perfusate had a high magnesium concentration $(10 \mathrm{mM})$ to prevent the activation of the NMDA receptors. This was followed by a 15-min 'adaptation' period at a physiological magnesium concentration $(1.19 \mathrm{mM})$ and a 30 -min 'ischemia' period during which the perfusate was gassed with $95 \% \mathrm{~N}_{2}$ and $5 \% \mathrm{CO}_{2}$ and contained no glucose. After ischemia, animals were exposed to a 'reperfusion' period that lasted 6,8 , or $12 \mathrm{~h}$ ( $\mathrm{n}=7$ per group), using the same perfusion solution as in the 'adaptation' period.

Frozen tissue fragments of cerebral cortex were homogenized, and the supernatants were prepared for Western blotting and enzyme activity assay, or followed by perfusion with fixative solution for immunohistochemistry, as described below.

Another group of rats $(n=28)$ (identified as the treatment animals) received the NO donor LA 419 (at $20 \mathrm{mg} / \mathrm{kg}$ of body weight), by oral gavage $1 \mathrm{~h}$ prior to ischemiareperfusion, following the same protocol as above. This group included treated non-ischemic controls $(n=7)$ and 3 groups of rats ( $\mathrm{n}=7$ per group) subjected to $30-\mathrm{min}$ ischemia and 6,8 , or $12 \mathrm{~h}$ of reperfusion.

Antisera. Rabbit antisera against nNOS, iNOS, and nitrotyrosine were produced in-house as previously described (26). We also used a commercial mouse monoclonal iNOS antibody (Transduction Laboratories, Lexington, KY, USA).

Immunohistochemical staining. Immunohistochemistry was performed as described (27). Briefly, the brains were fixed by transcardial perfusion with $350 \mathrm{ml} \mathrm{4 \%}(\mathrm{w} / \mathrm{v})$ paraformaldehyde in $0.1 \mathrm{M}$ phosphate buffer (PB), $\mathrm{pH} 7.4$, at the end of the experimental procedure. The brains were then removed, cut into blocks, post-fixed for $3 \mathrm{~h}$ at room temperature and cryoprotected by immersion in $30 \%(\mathrm{w} / \mathrm{v})$ sucrose in PB. Frozen serial coronal sections, $40-\mu \mathrm{m}$ thick, were cut with a Leitz sledge microtome, and free-floating sections were processed by the avidin-biotin peroxidase complex $(\mathrm{ABC})$ technique to visualize nNOS, iNOS, and nitrotyrosine immunoreactive sites. Photomicrographs were captured with a digital camera (Polaroid DMC IE, Cambridge, MA, USA) attached to a bright field microscope (Axioplan 2, Zeiss, Jena, Germany). The images were imported into Adobe Photoshop, version 5.5, at $300 \mathrm{dpi}$, cropped and corrected for brightness and contrast but not otherwise manipulated, and then transferred to Microsoft PowerPoint 2000 for plate production.

Immunohistochemical controls. No immunolabeling was observed when the primary antibodies were omitted or replaced with an equivalent concentration of preimmune or normal rabbit serum. The specificity of the nNOS antiserum was demonstrated by incubating the tissue sections with the primary antiserum preabsorbed (overnight at $4^{\circ} \mathrm{C}$ ) with $2 \mu \mathrm{g} /$ $\mathrm{ml}$ recombinant $\mathrm{nNOS}$. The specificity of the iNOS antiserum was shown by preabsorption with $10 \mathrm{nmol} / \mathrm{ml}$ of the respective immunising peptide. The specificity of the nitrotyrosine antiserum was demonstrated by preabsorption with free nitrotyrosine at $100 \mathrm{nmol} / \mathrm{ml}$. This procedure abolished immunostaining in all cases.

Western blotting. Western blotting studies were performed as previously described (26). Briefly, brains were removed at various times during the experimental perfusion procedure, or from control rats. Cortical tissues were homogenized. Homogenates were centrifuged, and the supernatants collected. Protein concentrations were determined by the method of Bradford (28), using bovine serum albumin as standard. Samples of supernatants were mixed 1:1 with $2 \mathrm{X}$ sample buffer and denatured at $95^{\circ} \mathrm{C}$ for $3 \mathrm{~min}$. SDS polyacrylamide gel electrophoresis was performed in 7.5 or $10 \%$ polyacrylamide gels with a $3.5 \%$ stacking gel and with $0.25 \mathrm{M}$ Tris-glycine, $\mathrm{pH} 8.3$ as the electrolyte buffer in a Bio-Rad 

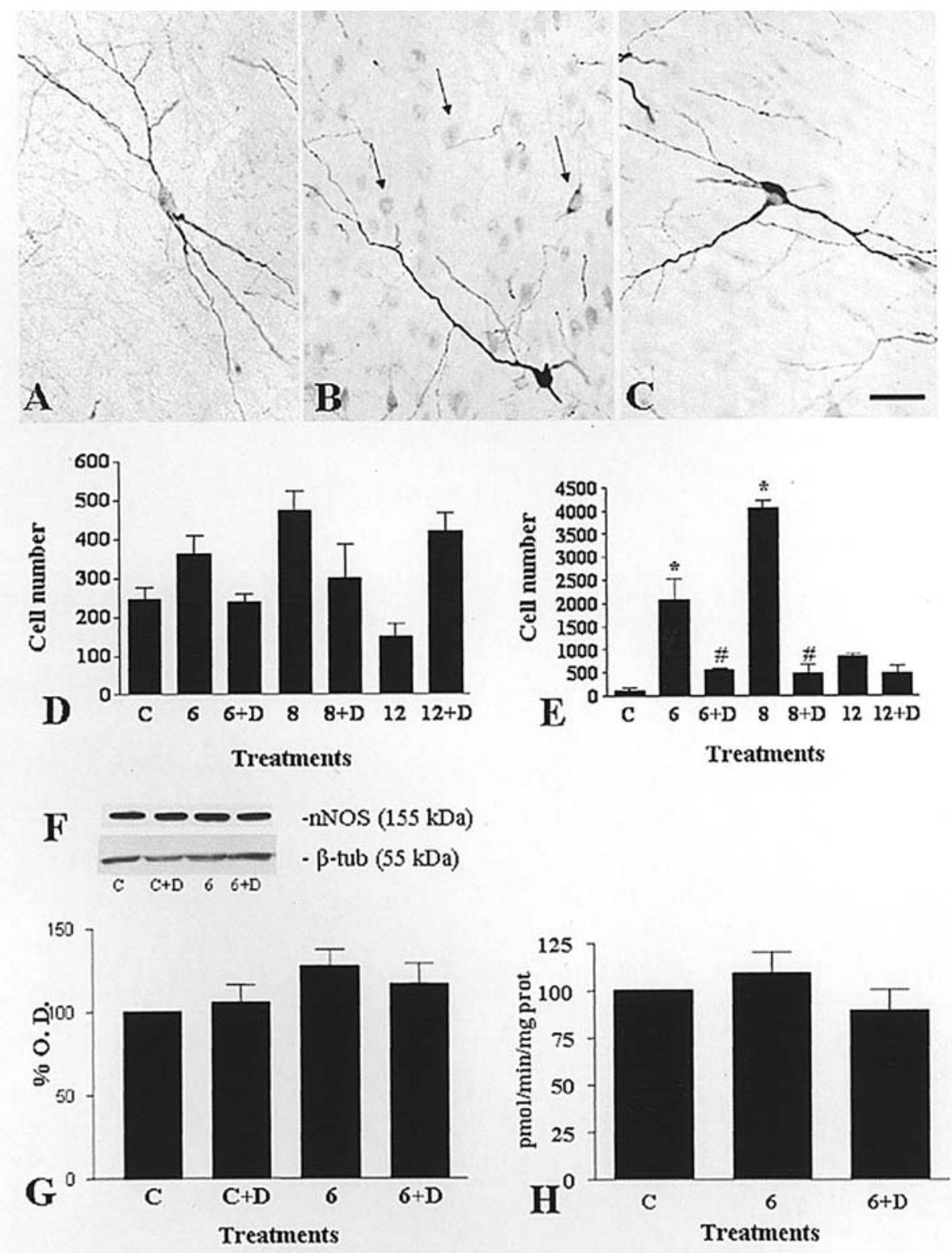

Figure 1. Expression of nNOS and $\mathrm{Ca}^{2+}$-dependent NOS activity in control and ischemic animals in the absence and presence of NO donor LA 419. Immunohistochemical staining for nNOS labels large interneurons (type I) in the cortex of control animals (A). After 30 min of ischemia and 8 h of reperfusion, type II neurons (arrows) became immunoreactive for nNOS (B). Treatment with LA 419 reduced nNOS immunoreactivity in type II neurons at the same time period (C). Bar $=60 \mu \mathrm{m}$. When the number of nNOS-IR type I (D) and type II (E) neurons were counted, differences were not significant in the large interneurons (D), but were highly significant in type II cells (E). * Statistically significant differences with control (p<0.001); ${ }^{*}$ statistically significant differences with untreated animals at the same time of reperfusion $(\mathrm{p}<0.001)$. Representative Western blotting of cortex extracts from these animals $(\mathrm{F})$ and densitometer quantification corrected by $ß$-tubulin values $(\mathrm{G})$ showed no significant differences in global $\mathrm{nNOS}$ expression. Biochemical analysis of Ca ${ }^{2+}-$ dependent NOS activity $(\mathrm{H})$ showed no difference between treatments as well. Bars represent mean \pm SEM of at least 3 independent repeats.

Mini-Protein II apparatus (Bio-Rad, Madrid, Spain). Proteins were electroblotted at $1.5 \mathrm{~mA} / \mathrm{cm}^{2}$ for $1 \mathrm{~h}$ onto $0.2-\mathrm{mm}$ polyvinylidene difluoride (PVDF) membranes (Immobilon-P, Millipore, Bedford, MA, USA) by means of a semidry transfer apparatus (Bio-Rad) for incubation with antibody. Non-specific binding sites were blocked for $1 \mathrm{~h}$ at room temperature with $5 \%(\mathrm{w} / \mathrm{v})$ dried defatted milk and $0.1 \%$ (v/v) Tween-20 in Tris-buffered saline (TBS), pH 7.6 (blocking solution). The membranes were then incubated with dilutions of the antisera in blocking solution overnight at $4^{\circ} \mathrm{C}$. After extensive washing in TBS, bound antibodies were revealed by the enhanced chemiluminescence kit including the appropriate secondary antibody conjugates
(Amersham Pharmacia Biotech, Cerdanyola, Spain) according to the manufacturer's instructions. The membranes were exposed to X-ray film and scanned with a computerassisted densitometer.

NOS activity assay. The activity of NOS in the supernatants of the brain extracts prepared for Western blotting was measured as the rate of conversion of radiolabeled arginine to citrulline in the assay as described (29). Briefly, the samples were incubated at $37^{\circ} \mathrm{C}$ with $\left[\mathrm{U}^{14} \mathrm{C}\right]$-L-arginine (Amersham) in buffer containing $50 \mathrm{mM} \mathrm{K \textrm {K } _ { 2 } \mathrm { PO } _ { 4 } , 1 \mathrm { mM } \mathrm { MgCl }} 2,0.2 \mathrm{mM}$ $\mathrm{CaCl}_{2}, 50 \mathrm{mM}$ L-valine, $1 \mathrm{mM}$ L-citrulline, $20 \mu \mathrm{M}$ L-arginine, $0.1 \mathrm{mM}$ NADPH, $10 \mu \mathrm{M}$ tetrahydrobiopterin and $1.5 \mathrm{mM}$ 

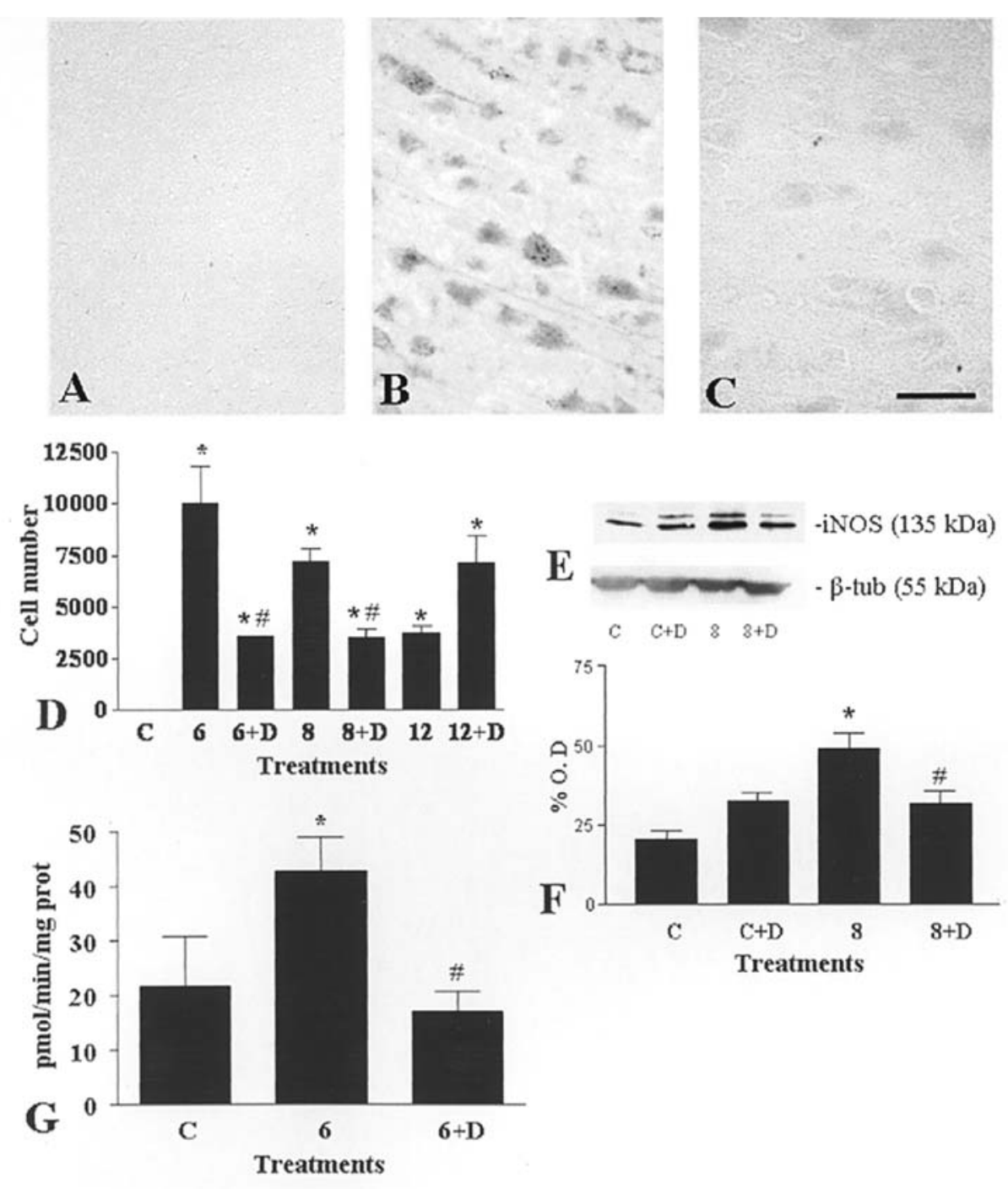

Figure 2. Expression of iNOS and $\mathrm{Ca}^{2+}$-independent NOS activity in control and ischemic animals in the absence and presence of NO donor LA 419. Immunohistochemical staining for iNOS in control animals (A) was negligible. After 30 min of ischemia and $6 \mathrm{~h}$ of reperfusion, untreated animals presented a granular staining pattern in the soma of cortical neurons (B), which disappeared in animals treated with the NO donor $(\mathrm{C})$. Bar $=60 \mu \mathrm{m}$. The number of iNOS-IR cells in defined areas of the cortex greatly increased after ischemia and reperfusion but was significantly reduced by treatment with LA 419 (D). *Statistically significant differences with control $(\mathrm{p}<0.01)$; "statistically significant differences with untreated animals at the same time of reperfusion $(\mathrm{p}<0.01)$. Representative Western blot of cortex extracts from these animals $(\mathrm{E})$ and densitometer quantification corrected by $ß$-tubulin values $(\mathrm{F})$ show a significant increase after $30 \mathrm{~min}$ of ischemia and $8 \mathrm{~h}$ of reperfusion. This increase in iNOS-IR was prevented by treatment with the NO donor. Biochemical analysis of $\mathrm{Ca}^{2+}$-independent NOS activity $(\mathrm{G})$ showed a significant increase in activity following ischemia and $6 \mathrm{~h}$ of reperfusion (p<0.05 compared to control) which was downregulated by LA 419 ( $<<0.01$ compared to untreated animals). Bars represent mean \pm SEM of at least 3 independent repeats.

dithiothreitol, in the presence or absence of L-NAME. The addition of $2 \mathrm{mM}$ ethylene glycol-bis(ß-aminoethyl ether) (EGTA) was used to differentiate between $\mathrm{Ca}^{2+}$-dependent and $\mathrm{Ca}^{+}{ }^{+}$-independent NOS activities. After $20 \mathrm{~min}$ of incubation, the reaction was terminated by adding AG 50W-X8 resin (Bio-Rad) to remove unreacted arginine, and the radioactivity remaining in the supernatant was counted in a liquid scintillation counter (Wallac 1410, Pharmacia).

Magnetic resonance imaging. Brains of NO donor-treated and untreated rats were analyzed by MRI as previously described (26). Images were acquired in a Bruker Biospec $47 / 40$ spectrometer, with a main field of $4.7 \mathrm{~T}$ and a $40-\mathrm{cm}$ bore. This magnet is equipped with an unshielded gradient coil with a maximum strength of $372 \mathrm{mT} / \mathrm{m}$. The RF coil, acting as a transmitter and receiver, was a 30-mm-diameter surface coil placed just on top of the head of the rat. Initially, localization fast spin echo images were acquired both in the coronal and in the sagittal directions, and a single coronal slice was selected for imaging, located approximately $2.3 \mathrm{~mm}$ anterior to the bregma. Diffusion-weighted images were acquired with a $30 \times 30 \mathrm{~mm}$ field of view, a slice thickness of $1 \mathrm{~mm}$, and a 256x64 acquisition matrix, using a sliceselective spin echo sequence, with one slice, two averages, and five different values of the diffusion gradient, $\mathrm{TE}=50$, $\mathrm{TR}=200, \mathrm{~T}=20.56$, and $\delta=10 \mathrm{msec}$. Spatial resolution was therefore 1,000 (slice thickness) x $469 \times 117 \mu \mathrm{m}$. Apparent diffusion coefficient (ADC) values were calculated by fitting intensity values with a package included in the imaging software ParaVision (Bruker, Ettlingen, Germany).

Statistical analysis. The number of neural structures expressing nNOS, iNOS, or nitrotyrosine immunoreactivity that were found in a columnar area of the cortex of $1.2 \mathrm{~mm}$ 

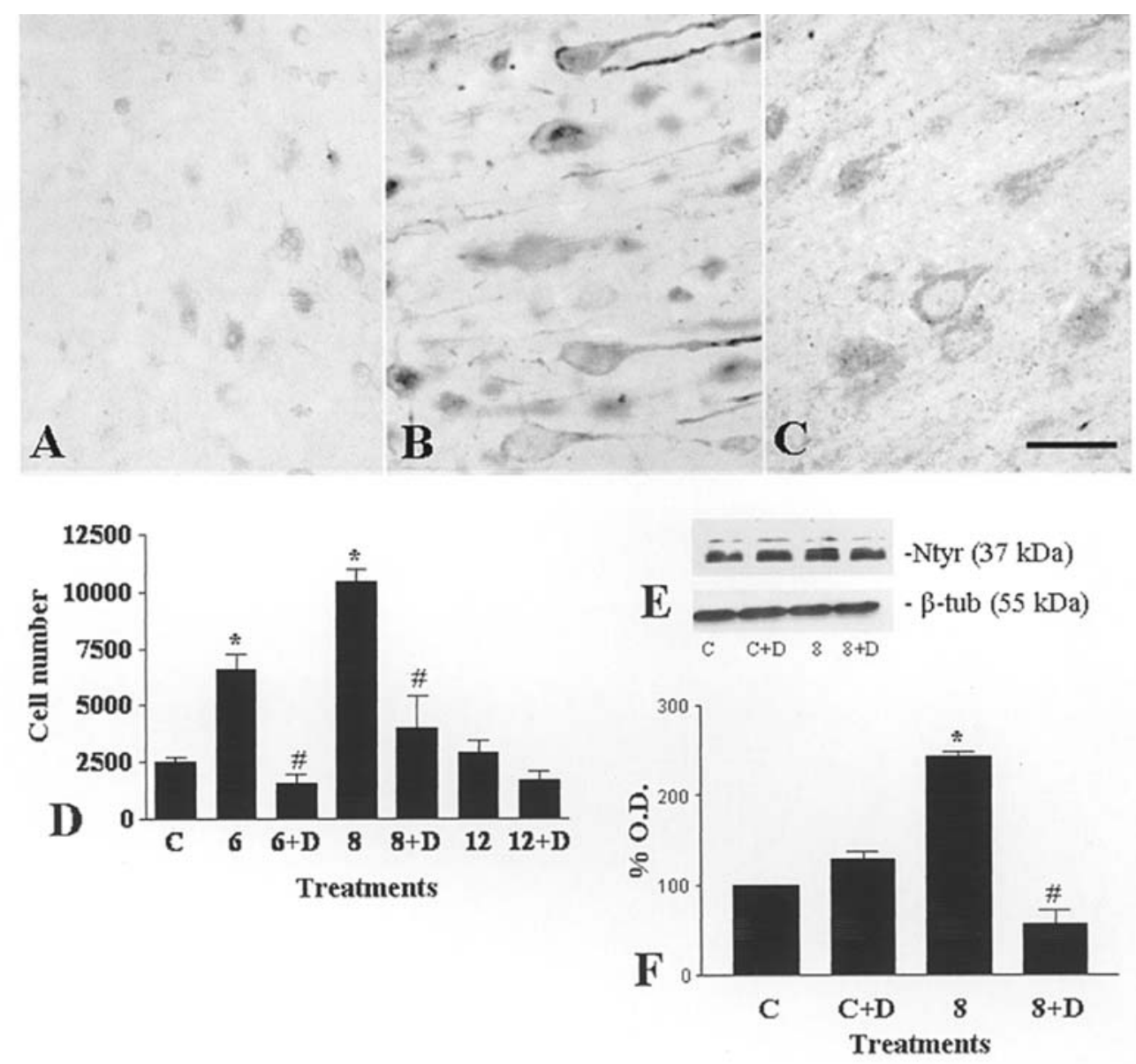

Figure 3. Expression of nitrotyrosine in control and ischemic animals in the absence and presence of NO donor LA 419. Immunohistochemical staining for nitrotyrosine in control animals (A) was low. Following ischemia and $8 \mathrm{~h}$ of reperfusion nitrotyrosine-IR was found in the soma and apical dendrites of pyramidal neurons (B). The increase in nitrotyrosine-IR was less apparent in the presence of LA $419(\mathrm{C})$. Bar $=40 \mu \mathrm{m}$. The number of nitrotyrosine-IR cells in defined areas of the cortex increased after ischemia and reperfusion but was significantly reduced by treatment with LA 419 (D). *Statistically significant differences with control $(\mathrm{p}<0.001)$; " statistically significant differences with untreated animals at the same time of reperfusion ( $<<0.01)$. Representative Western blot of cortex extracts from these animals (E) and densitometer quantification corrected by ß-tubulin values (F) showed a significant increase after 30 min of ischemia and $8 \mathrm{~h}$ of reperfusion. This increase in nitrotyrosine-IR was prevented by treatment with the NO donor. Bars represent the mean \pm SEM of at least 3 independent repeats.

(length) by $2.5 \mathrm{~mm}$ (deep), was counted in 9 randomly chosen areas per experimental animal. The data obtained were analyzed by the Dunnet test. Western blotting data were analysed by a t-test to compare groups using Prism 3.0 computer software. Analysis of the differences between treated and untreated rats subjected to MRI was performed by 2-way ANOVA. All results are expressed as mean \pm SEM. $\mathrm{p}$ values $<0.05$ were considered statistically significant.

\section{Results}

The brain cortices of treated and untreated animals were studied by immunohistochemistry and Western blotting using specific antibodies against nNOS, iNOS, and nitrotyrosine. In addition, biochemical NOS activity was also assessed. The results presented here describe specifically the effects of ischemia-reperfusion on the fronto-parietal cortex; however similar changes were found in other cortical areas.

Neuronal NOS and $\mathrm{Ca}^{2+}$-dependent activity. There are two types of nNOS-immunoreactive (IR) neurons in the cortex of the rat (Fig. 1A-C). The main difference is their larger (type I) or smaller (type II, arrows in Fig. 2B) size, as previously described (26). The number of neurons in the defined areas (27 $\mathrm{mm}^{2} /$ animal) was determined in all animals and comparisons were made between treated and untreated animals at different times of reperfusion (Fig. 1D and E).

In the case of the large nNOS-IR neurons (type I), no statistically significant differences were found when comparing treated and untreated animals or the same group of animals at different time points (Fig. 1A-D). However, the small nNOS-IR neurons (type II) presented a notable behavior. The number of type II neurons in control rats was very low (Fig. 1A and E). The number of type II positive neurons increased steadily after 6 or $8 \mathrm{~h}$ of reperfusion ( $\mathrm{p}<0.001$ compared to control) in the untreated rats (Fig. 1B and E). On the other hand, treatment with LA 419 resulted in a very significant reduction in the number of type II nNOS-IR neurons in the rat cortex $(\mathrm{p}<0.001$ at 6 and $8 \mathrm{~h}$ compared to untreated animals at the same time of reperfusion; Fig. 1C and E). Western blotting for nNOS in these animals showed no statistically significant change (Fig. 1F and G). No changes were observed when 


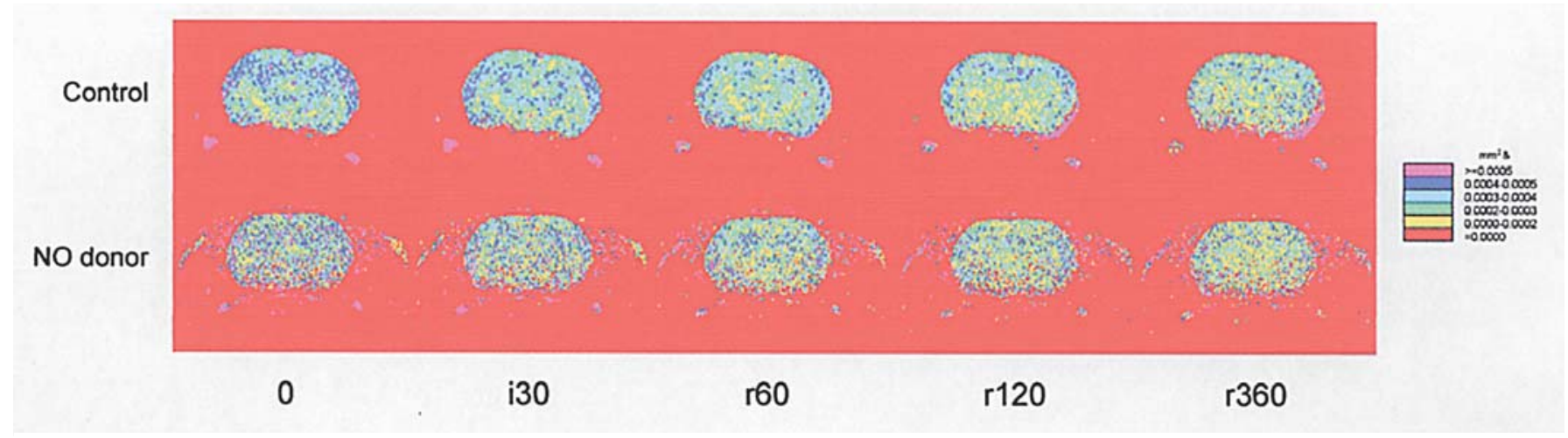

Figure 4. Coronal images of rat brain analyzed by MRI. As expressed by the scale to the right, colder colors represent higher ADC and warmer colors lower ADC values. The upper row shows the brain of the same rat, which was not treated with NO-donor at different time periods during global ischemia (i) and reperfusion (r). Numbers are in minutes. The lower row of images represents the brain of another rat, treated with NO-donor as described in Materials and methods at the same periods of time.

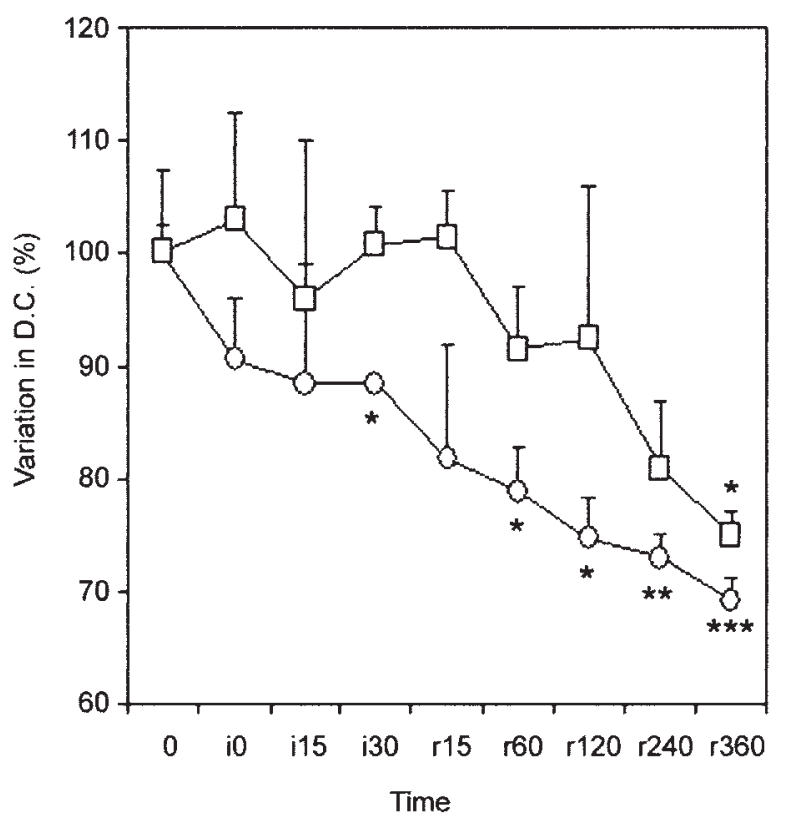

Figure 5. Quantification of the ADC values obtained in the cortex of NOdonor treated (squares) and untreated (circles) rats at different times of ischemia (i) and reperfusion (r). Numbers represent minutes. Each point represents the mean \pm SD of 3 independent measurements. Statistically significant differences with the same animal before the perfusion began $(0)$, expressed as $100 \%$, are indicated with asterisks: ${ }^{*} \mathrm{p}<0.005,{ }^{* *} \mathrm{p}<0.001$, ${ }^{* * * *} \mathrm{p}<0.0001$.

comparing treated versus untreated control animals. The production of NO by nNOS is a $\mathrm{Ca}^{2+}$-dependent enzymatic activity whereas iNOS activity is $\mathrm{Ca}^{2+}$-independent (29). $\mathrm{Ca}^{2+}$-dependent NOS activity in the cortex of ischemic rats did not change when compared to normal controls or to NO donor-treated animals (Fig. 1H), suggesting that the increase in immunoreactive type II neurons may not have an important contribution to total nNOS activity.

Inducible NOS and $\mathrm{Ca}^{2+}$-independent activity. The number of iNOS-IR structures in the cortex of control animals was practically non-existent (Fig. 2A and D). iNOS expression increased greatly after ischemia showing a zenith after $6 \mathrm{~h}$ of reperfusion $(\mathrm{p}<0.001)$ that slowly diminished over time but was still high at $12 \mathrm{~h}(\mathrm{p}<0.01)$ (Fig. 2D). The immunoreactive pattern for iNOS was characteristically granular and located mainly in the neuronal soma and the wide proximal dendritic processes (Fig. 2B). Both the number of iNOS-IR neurons and the intensity of their immunoreactivity were significantly decreased in the presence of LA 419 (Fig. 2C and D). Western blots of protein extracts obtained from the cortices of the experimental animals were in agreement with the immunohistochemical data (Fig. 2E and F). Tissues extracted after ischemia and 6 or $8 \mathrm{~h}$ of reperfusion presented more intense iNOS-IR bands than control animals $(\mathrm{p}<0.01)$. Treatment with the NO donor LA 419 reduced iNOS-IR back to normal levels. These results were confirmed by enzymatic assays (Fig. 2G). $\mathrm{Ca}^{2+-}$-independent NOS activity increased at $6 \mathrm{~h}$ of reperfusion when compared with controls $(\mathrm{p}<0.05)$, whereas treatment with LA 419 reduced $\mathrm{Ca}^{2+}$-independent NOS activity to below basal levels $(\mathrm{p}<0.01$ compared to untreated ischemic rats). The same trend was observed after 8 and $12 \mathrm{~h}$ of reperfusion but the total intensity of the signal was lower (data not shown).

Nitrotyrosine. Excessive production of NO leads, among other things, to protein nitration, specifically at exposed tyrosine residues (7). Therefore the presence of nitrotyrosine can be used as a surrogate marker of pathologic NO production. In our rat model of brain ischemia, nitrotyrosineIR was very low in the cerebral cortex of control animals (Fig. 3A), but steadily increased after 6 and $8 \mathrm{~h}$ of reperfusion following global ischemia, and came back to normal levels after $12 \mathrm{~h}$ of reperfusion (Fig. 3B and D). The increase in nitrotyrosine-IR was observed both in the neurons (Fig. 3B) and in glial cells (results not shown). In many cases, nitrotyrosine-IR neurons presented a morphology consistent with neuronal degeneration (data not shown). As with iNOS, the pathological increase in nitrotyrosine-IR was efficiently prevented by treatment with LA 419 (Fig. 3C and D). Western blot analyis of nitrotyrosine-positive bands predictably showed a significant increase after ischemia and $8 \mathrm{~h}$ of reperfusion $(p<0.001)$, which did not appear in animals treated with the drug (Fig. 3E and F). Similar patterns were obtained at 6 and $12 \mathrm{~h}$ of reperfusion (data not shown). 
Magnetic resonance imaging in global ischemia. The brain maps in control animals (before any treatment) showed a

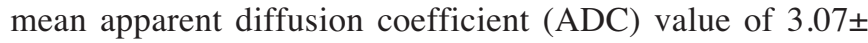
$0.08 \times 10^{-6} \mathrm{~cm}^{2} / \mathrm{sec}$ (Fig. 4). The untreated control group showed a notable decrease in ADC during ischemia and reperfusion (Figs. 4 and 5), reaching significantly lower values of ADC after $30 \mathrm{~min}$ of ischemia, even before the reperfusion period began. For the animals treated with the NO donor there was also a slight decline in ADC, but this value did not reach statistically significant differences compared with the control (same animals at time $=0$ ) until after $6 \mathrm{~h}$ of reperfusion (Figs. 4 and 5). Comparison of ADC values in the cortex of both groups of animals was performed by a 2-way ANOVA. Both groups were statistically different with the following parameters; $F=21.717$ and $p<0.0001$.

\section{Discussion}

We have shown that the novel NO donor LA 419 reduces ischemic damage in an experimental model of global brain ischemia. We focused on the cerebral cortex and thus cannot predict the effects of this drug in other regions. Previous studies have produced apparently conflicting results on the role played by $\mathrm{NO}$ in cerebral ischemia. On the one hand, nNOS- and iNOS-deficient mice suffered smaller infarcts than their wild-type littermates following experimental ischemia $(13,18)$, and something similar occurred when animals were treated with NOS inhibitors (30-35). However, the lack of NO elicited by either genetic manipulation or NOS inhibitors had detrimental effects for normal brain physiology, especially related to cerebral blood flow and disturbed neuronal function $(13,17,36)$. To note, the administration of $\mathrm{NO}$ donors such as sodium nitroprusside, DETA/NONOate, or 3-morpholinosydnonimine, also reduces infarct size (37-39). This apparent controversy may be resolved by considering the total levels of NO available in the tissue at a particular time. It has been suggested that low levels of NO are neuro-protective due to the beneficial effects of NO on vasodilatation and normal neuronal function, whereas high levels of NO may lead to the formation of free radicals and deleterious biochemical modifications of cell components (7). In addition, NO donors downregulate iNOS expression and upregulate expression of eNOS $(35,40)$. This beneficial effect may be mediated by activation of the glucocorticoid receptor and the glucocorticoid response element, which would reduce iNOS expression (41), thus avoiding the robust production of NO characteristic of this NOS isoform.

In our global cerebral ischemia model, we have described a modest upregulation of nNOS following ischemia and reperfusion which was not followed by a significant increase in $\mathrm{Ca}^{2+}$-dependent NOS enzymatic activity. This disconnection between increased immunoreactivity and no change in activity has been previously reported and may be due to a lack of NADPH diaphorase activity in the newly synthesized nNOS (42).

In contrast, iNOS immunoreactivity and $\mathrm{Ca}^{2+}$-independent enzymatic NOS activity increased sharply after ischemia and reperfusion, suggesting that this enzyme is mainly responsible for the NO-related damage caused by cerebral infarcts. Again, the NO donor LA 419 completely prevented the pathological overexpression of iNOS as shown by immunohistochemistry, Western blotting, and iNOS activity assays. We have studied the effect of LA 419 on iNOS expression in an in vitro cellular model of the transition from monocyte to macrophage. The levels of iNOS were followed by Western blotting at day 1 (adherent monocyte) and 3 (early macrophage) of the transition process. Treatment of the cells with $5 \mu \mathrm{M}$ LA 419 reduced iNOS expression by $50 \pm 17 \%$ at day 1 and by $44 \pm 10 \%$ at day 3 (unpublished results).

Nitrotyrosine staining was mainly found in astroglia, identifying this cell type as the most prone to protein nitration in the brain. The high susceptibility of the astrocytes to nitration has been described also in other pathologies (7).

In our global model, we have seen a clear decrease in ADC following ischemia-reperfusion. This was previously described by our group (26) and interpreted as a consequence of the increase in cytotoxic intracellular edema caused by the ischemia-induced breakdown of cell membrane transporters. A decrease in ADC has been related to ischemic injury by others as well (43).

In summary, we have shown that LA 419 prevented the modifications induced by cerebral ischemia in the nitrergic system of the brain and the resulting reduction in ADC, suggesting a potential beneficial use of this NO donor in stroke and in other conditions where an increase in NO production is relevant. Further experiments are needed to understand the mechanism of action of this new drug and whether it may be useful for clinical treatment.

\section{Acknowledgments}

The authors gratefully acknowledge the excellent technical assistance of Ms. Africa Sandonís and Ms. Encarnación Fernández. The authors are supported by the Ministry of Science and Education of Spain, grant nos. EET2001/ 4844/02, SAF2003/04398/C02/01, and BFU2004/02838.

\section{References}

1. Mohr JP, Caplan LR, Melski JW, Goldstein RJ, Duncan GW, Kistler JP, Pessin MS and Bleich HL: The Harvard Cooperative Stroke Registry: a prospective registry. Neurology 28: 754-762, 1978.

2. Iadecola C: Mechanisms of cerebral ischemic damage. In: Cerebral Ischemia: Molecular and Cellular Pathophysiology. Walz W (ed). Humana Press, Inc., Totowa, NJ, pp3-36, 1999.

3. Adams H, Adams R, Del ZG and Goldstein LB: Guidelines for the early management of patients with ischemic stroke: 2005 guidelines update a scientific statement from the Stroke Council of the American Heart Association/American Stroke Association. Stroke 36: 916-923, 2005.

4. Willmot M, Gibson C, Gray L, Murphy S and Bath P: Nitric oxide synthase inhibitors in experimental ischemic stroke and their effects on infarct size and cerebral blood flow: A systematic review. Free Radic Biol Med 39: 412-425, 2005.

5. Bode-Boger SM and Kojda G: Organic nitrates in cardiovascular disease. Cell Mol Biol (Noisy-le-grand) 51: 307-320, 2005.

6. Jones SP and Bolli R: The ubiquitous role of nitric oxide in cardioprotection. J Mol Cell Cardiol 40: 16-23, 2006.

7. Rodrigo J, Fernandez AP, Serrano J, Peinado MA and Martinez A: The role of free radicals in cerebral hypoxia and ischemia. Free Radic Biol Med 39: 26-50, 2005.

8. Lei B, Adachi N, Nagaro T, Arai T and Koehler RC: Nitric oxide production in the CA1 field of the gerbil hippocampus after transient forebrain ischemia: effects of 7-nitroindazole and NG-nitro-L-arginine methyl ester. Stroke 30: 669-677, 1999. 
9. Olesen SP, Moller A, Mordvintcev PI, Busse R and Mulsch A: Regional measurements of NO formed in vivo during brain ischemia. Acta Neurol Scand 95: 219-224, 1997.

10. Togashi H, Mori K, Ueno K, Matsumoto M, Suda N, Saito H and Yoshioka M: Consecutive evaluation of nitric oxide production after transient cerebral ischemia in the rat hippocampus using in vivo brain microdialysis. Neurosci Lett 240: 53-57, 1998.

11. Yoshida T, Waeber C, Huang Z and Moskowitz MA: Induction of nitric oxide synthase activity in rodent brain following middle cerebral artery occlusion. Neurosci Lett 194: 214-218, 1995.

12. O'Mahony D and Kendall MJ: Nitric oxide in acute ischaemic stroke: a target for neuroprotection. J Neurol Neurosurg Psychiatry 67: 1-3, 1999.

13. Loihl AK, Asensio V, Campbell IL and Murphy S: Expression of nitric oxide synthase (NOS)-2 following permanent focal ischemia and the role of nitric oxide in infarct generation in male, female and NOS-2 gene-deficient mice. Brain Res 830: 155-164, 1999.

14. Sun Y, Carretero OA, Xu J, Rhaleb NE, Wang F, Lin C, Yang JJ, Pagano PJ and Yang XP: Lack of inducible NO synthase reduces oxidative stress and enhances cardiac response to isoproterenol in mice with deoxycorticosterone acetate-salt hypertension. Hypertension 46: 1355-1361, 2005.

15. Huang Z, Huang PL, Ma J, Meng W, Ayata C, Fishman MC and Moskowitz MA: Enlarged infarcts in endothelial nitric oxide synthase knockout mice are attenuated by nitro-L-arginine. J Cereb Blood Flow Metab 16: 981-987, 1996.

16. Su J, Tse J, Scholz PM and Weiss HR: Alterations in ventricular myocyte contraction caused by C-type natriuretic peptide and nitric oxide in eNOS-/- mice. J Mol Cell Cardiol 39: 920-928, 2005.

17. Tagami M, Ikeda K, Nara Y, Fujino H, Kubota A, Numano F and Yamori Y: Detailed examination of vascular lesions triggered by an inhibitor of endothelium-derived relaxing factor. Lab Invest 72: 174-182, 1995.

18. Huang Z, Huang PL, Panahian N, Dalkara T, Fishman MC and Moskowitz MA: Effects of cerebral ischemia in mice deficient in neuronal nitric oxide synthase. Science 265: 1883-1885, 1994.

19. Saraiva RM, Minhas KM, Raju SV, Barouch LA, Pitz E, Schuleri KH, Vandegaer K, Li D and Hare JM: Deficiency of neuronal nitric oxide synthase increases mortality and cardiac remodeling after myocardial infarction: role of nitroso-redox equilibrium. Circulation 112: 3415-3422, 2005.

20. Sampei K, Mandir AS, Asano Y, Wong PC, Traystman RJ, Dawson VL, Dawson TM and Hurn PD: Stroke outcome in double-mutant antioxidant transgenic mice. Stroke 31: 2685-2691, 2000.

21. McCullough LD, Zeng Z, Blizzard KK, Debchoudhury I and Hurn PD: Ischemic nitric oxide and poly (ADP-ribose) polymerase-1 in cerebral ischemia: male toxicity, female protection. J Cereb Blood Flow Metab 25: 502-512, 2005.

22. Lácer: Derivatives of isosorbid mononitrate as vasodilator agents with reduced tolerance. International Patent. 2005.

23. Vilahur G, Segales E, Casani L and Badimon L: A novel antiischemic nitric oxide donor inhibits thrombosis without modifying haemodynamic parameters. Thromb Haemost 91: 1035-1043, 2004.

24. Salas E and Badimón L: Líneas de investigación en el uso terapéutico del óxido nítrico. Rev Esp Cardiol (Suppl) 6: 51A58A, 2006.

25. Serrano J, Alonso D, Encinas JM, Lopez JC, Fernandez AP, Castro-Blanco S, Fernandez-Vizarra P, Richart A, Bentura ML, Santacana M, Uttenthal LO, Cuttitta F, Rodrigo J and Martinez A: Adrenomedullin expression is up-regulated by ischemiareperfusion in the cerebral cortex of the adult rat. Neuroscience 109: 717-731, 2002.

26. Alonso D, Serrano J, Rodriguez I, Ruiz-Cabello J, Fernandez AP, Encinas JM, Castro-Blanco S, Bentura ML, Santacana M, Richart A, Fernandez-Vizarra P, Uttenthal LO and Rodrigo J: Effects of oxygen and glucose deprivation on the expression and distribution of neuronal and inducible nitric oxide synthases and on protein nitration in rat cerebral cortex. J Comp Neurol 443: 183-200, 2002.
27. Rodrigo J, Alonso D, Fernandez AP, Serrano J, Richart A, Lopez JC, Santacana M, Martinez-Murillo R, Bentura ML, Ghiglione $\mathrm{M}$ and Uttenthal LO: Neuronal and inducible nitric oxide synthase expression and protein nitration in rat cerebellum after oxygen and glucose deprivation. Brain Res 909: 20-45, 2001

28. Bradford MM: A rapid and sensitive method for the quantitation of microgram quantities of protein utilizing the principle of protein-dye binding. Anal Biochem 72: 248-254, 1976.

29. Radomski MW, Vallance P, Whitley G, Foxwell N and Moncada S: Platelet adhesion to human vascular endothelium is modulated by constitutive and cytokine induced nitric oxide. Cardiovasc Res 27: 1380-1382, 1993.

30. Haga KK, Gregory LJ, Hicks CA, Ward MA, Beech JS, Bath PW, Williams SC and O'Neill MJ: The neuronal nitric oxide synthase inhibitor, TRIM, as a neuroprotective agent: effects in models of cerebral ischaemia using histological and magnetic resonance imaging techniques. Brain Res 993: 42-53, 2003.

31. Iadecola $\mathrm{C}$, Zhang $\mathrm{F}$ and $\mathrm{Xu} \mathrm{X}$ : Inhibition of inducible nitric oxide synthase ameliorates cerebral ischemic damage. Am J Physiol 268: R286-R292, 1995.

32. Cockroft KM, Meistrell M III, Zimmerman GA, Risucci D, Bloom O, Cerami A and Tracey KJ: Cerebroprotective effects of aminoguanidine in a rodent model of stroke. Stroke 27: 1393-1398, 1996.

33. Nagayama M, Zhang F and Iadecola C: Delayed treatment with aminoguanidine decreases focal cerebral ischemic damage and enhances neurologic recovery in rats. J Cereb Blood Flow Metab 18: 1107-1113, 1998.

34. Cash D, Beech JS, Rayne RC, Bath PM, Meldrum BS and Williams SC: Neuroprotective effect of aminoguanidine on transient focal ischaemia in the rat brain. Brain Res 905: 91-103, 2001.

35. Kuo YR, Wang FS, Jeng SF, Huang HC, Wei FC and Yang KD: Nitrosoglutathione modulation of platelet activation and nitric oxide synthase expression in promotion of flap survival after ischemia/reperfusion injury. J Surg Res 119: 92-99, 2004.

36. Nelson RJ, Demas GE, Huang PL, Fishman MC, Dawson VL, Dawson TM and Snyder SH: Behavioural abnormalities in male mice lacking neuronal nitric oxide synthase. Nature 378: 383-386, 1995.

37. Salom JB, Orti M, Centeno JM, Torregrosa G and Alborch E: Reduction of infarct size by the NO donors sodium nitroprusside and spermine/NO after transient focal cerebral ischemia in rats. Brain Res 865: 149-156, 2000.

38. Zhang R, Zhang L, Zhang Z, Wang Y, Lu M, Lapointe M and Chopp M: A nitric oxide donor induces neurogenesis and reduces functional deficits after stroke in rats. Ann Neurol 50: 602-611, 2001.

39. Coert BA, Anderson RE and Meyer FB: Effects of the nitric oxide donor 3-morpholinosydnonimine (SIN-1) in focal cerebral ischemia dependent on intracellular brain $\mathrm{pH}$. J Neurosurg 97: 914-921, 2002.

40. De AJ, Cardenas A, Moro MA, Leza JC, Lorenzo P, Bosca L and Lizasoain I: Down-regulation of neuronal nitric oxide synthase by nitric oxide after oxygen-glucose deprivation in rat forebrain slices. J Neurochem 72: 248-254, 1999.

41. Ji JY and Diamond SL: Exogenous nitric oxide activates the endothelial glucocorticoid receptor. Biochem Biophys Res Commun 318: 192-197, 2004.

42. Encinas JM, Fernandez AP, Salas E, Castro-Blanco S, Munoz P, Rodrigo J and Serrano J: Nitric oxide synthase and NADPHdiaphorase after acute hypobaric hypoxia in the rat caudate putamen. Exp Neurol 186: 33-45, 2004.

43. Albensi BC, Schweizer MP, Rarick TM and Filloux F: Magnetic resonance imaging of hypoxic-ischemic brain injury in the neonatal rat. Invest Radiol 33: 377-385, 1998. 